\author{
ARTIGO \\ do https://doi.org/10.22481/praxisedu.v16i37.6190
}

\title{
EDUCAÇÃO SUPERIOR: UM DIREITO DE TODOS?
}

\author{
HIGHER EDUCATION: A RIGHT OF EVERYONE?
}

EDUCACIÓN SUPERIOR: ¿UN DERECHO DE TODOS?

\author{
Jemina de Araújo Moraes Andrade \\ Instituto Federal do Amapá - Brasil
}

\author{
Helena Cristina Guimarães Queiroz Simões \\ Universidade Federal do Amapá - Brasil
}

\begin{abstract}
Resumo: O presente artigo visa propor algumas reflexões sobre a educação superior enquanto direito humano fundamental, bem como o alcance de seu acesso, considerando que embora contemplado formalmente, necessita materializar-se, e, ainda que dados demonstrem o processo de expansão da educação superior no Brasil, a realidade demonstra a ampliação de um acesso que privilegia a quantidade em detrimento da qualidade. Assim, pretende-se analisar como se configura o direito a educação superior no Brasil, contextualizando de forma breve o processo histórico da educação superior no país; apresentar a concepção de educação como um direito de todos(as) e evidenciar se sua expansão significou maior abrangência e qualidade no processo formativo. A pesquisa pautou-se nos estudos sobre o direito humano fundamental à educação e a mercantilização da educação superior. A metodologia adotada foi de caráter histórico-crítica, com abordagem qualitativa. As evidências conclusivas demonstram uma educação superior negada, cuja expansão transformou pessoas sem diploma em invisíveis diplomados. Descumpre-se, portanto, o verdadeiro direito humano fundamental à educação superior pois esta não se efetiva como mera entrega de um produto e tampouco se encerra com o simples ingresso.
\end{abstract}

Palavras chave: Direito à educação. Direito Humano. Educação Superior.

\begin{abstract}
This article aims to propose some reflections on higher education as a fundamental human right, as well as the scope of its access, considering that although formally contemplated, it needs to materialize, and although data demonstrate the process of expansion of higher education in Brazil , reality demonstrates the expansion of access that privileges quantity over quality. Thus, we intend to analyze how the right to higher education in Brazil is configured, briefly contextualizing the historical process of higher education in the country; present the conception of education as a right of all and show if its expansion meant greater comprehensiveness and quality in the formative process. The research was based on studies on the fundamental human right to education and the commodification of higher education. The adopted methodology was of historical-critical character, with qualitative approach. The conclusive evidence demonstrates a denied higher education, the expansion of which has turned ungraded people into invisible graduates. Therefore, the true fundamental human right to higher education is ignored, since it is not effective as a product, nor is it simply terminated by admission.
\end{abstract}

Keywords: Right to education. Human rights. College education. 
Resumen: Este artículo tiene como objetivo proponer algunas reflexiones sobre la educación superior como un derecho humano fundamental, así como el alcance de su acceso, considerando que, aunque se contempla formalmente, necesita materializarse, y aunque los datos demuestran el proceso de expansión de la educación superior en Brasil , la realidad demuestra la expansión del acceso que privilegia la cantidad sobre la calidad. Por lo tanto, pretendemos analizar cómo se configura el derecho a la educación superior en Brasil, contextualizando brevemente el proceso histórico de la educación superior en el país; presentar la concepción de la educación como un derecho de todos y mostrar si su expansión significó una mayor amplitud y calidad en el proceso formativo. La investigación se basó en estudios sobre el derecho humano fundamental a la educación y la mercantilización de la educación superior. La metodología adoptada fue de carácter histórico-crítico, con enfoque cualitativo. La evidencia concluyente demuestra una educación superior negada, cuya expansión ha convertido a personas sin calificación en graduados invisibles. Por lo tanto, el verdadero derecho humano fundamental a la educación superior no se tiene en cuenta, ya que no es efectivo como una mera entrega de un producto, ni simplemente se termina con la admisión.

Palabras clave: Derecho a la educación. Derechos humanos. Educación universitaria.

\section{Introdução}

Existem inúmeros documentos internacionais que preveem a educação como um direito fundamental, dentre eles podemos citar a Declaração Universal dos Direitos Humanos que, em seu art. 26, enuncia que toda pessoa tem direito à educação, devendo ser orientada no sentido do pleno desenvolvimento da personalidade humana, do fortalecimento e do respeito aos direitos humanos e as liberdades fundamentais (ONU, 1948).

Seguindo as diretrizes estabelecidas pelos órgãos e documentos internacionais dos quais o Brasil é signatário, o legislador constituinte estabeleceu na Constituição Federal de 1988, no seu artigo $6^{\circ}$, a Educação no rol dos direitos fundamentais na categoria dos direitos sociais, prevendo em seu art. 205 como "um direito de todos e dever do Estado e da família". No ordenamento jurídico brasileiro, a oferta está sistematizada na educação básica ${ }^{1}$ e na educação superior $^{2}$, sendo essa última, objeto desse estudo (BRASIL, 1988; BRASIL, 1996).

Cabe frisar que, apesar dos avanços normativos no sentido de tornar a educação como um direito social, pertencente a toda coletividade, há uma problemática estabelecida, pois, de um lado, existem inúmeros estudos que apontam para o crescimento/expansão da educação superior no Brasil, fruto de diálogos e negociações orientadas a construção de políticas públicas que focalizem questões de acesso, mas, por outro lado, estudos apontam que poucos

\footnotetext{
${ }^{1}$ Vide art. $4^{\circ}$ e art. 21, I da Lei 9.394/96 - oferta da educação infantil, ensino fundamental e ensino médio.

${ }^{2}$ Art. 44 da Lei 9.394/96 - compreendida com cursos sequenciais por campo de saber, de diferentes níveis de abrangência; cursos de graduação (bacharelados, licenciaturas e tecnólogos) e a pós-graduação, compreendendo programas de mestrado e doutorado, cursos de especialização, aperfeiçoamento e outros, abertos a candidatos diplomados em cursos de graduação e que atendam às exigências das instituições de ensino; de extensão, abertos a candidatos que atendam aos requisitos estabelecidos em cada caso pelas instituições de ensino.
} 
são os avanços acerca das políticas para promoção da inclusão, permanência e sucesso na conclusão do curso superior (MINTO, 2006; SILVA JÚNIOR, 2017; MACIEL; LIMA; GIMENEZ, 2016).

O direito à educação é um dos principais direitos sociais consagrados na Carta Magna. No entanto, no que tange a educação superior, Silva Júnior (2017) assevera que as Instituições de Ensino Superior (IES) estariam deixando de cumprir sua função social, a de formação humana, produção do conhecimento e pensamento crítico, além de promover cidadania como indutora de mudanças na sociedade. Ao contrário, vem passando a ocupar um lugar social e econômico nos moldes do mercado.

Nesse sentido, propõe-se nesse estudo ${ }^{3}$, reflexões sobre a existência do direito à educação superior e ao mesmo tempo a aparente negação a esse direito, pois ainda que se verifique o avanço legislativo que estabeleça esta garantia, a sua implementação nas IES parece não acompanhar o patamar qualitativo esperado.

Assim, o presente estudo tem como problema analisar como vem se apresentando o direito a educação superior no Brasil, considerando seu processo de expansão. Para isso, o trabalho está organizado em três momentos, quais sejam: contextualizar de forma breve o processo histórico da educação superior no Brasil; depois, abordar sobre o direito à educação, com enfoque na sustentação deste como um direito humano fundamental. Por fim, problematizar a educação enquanto um direito de todos, frente ao cenário atual de mercantilização da educação superior apoiado por políticas públicas e pela atuação de algumas categorias de IES.

Desse modo, o presente estudo é de abordagem qualitativa, e está fundamentado no método histórico-crítico, apoiando-se em fontes documentais e bibliográficas, dentre as quais se destacam: a Constituição Federal (1988) e os estudos de Bianchetti e Sguissardi (2017), Candau (2012), Bobbio (2004), Silva Júnior (2017), Zenaide (2001; 2010).

\section{Breve histórico sobre a educação superior no Brasil}

A educação superior é o nível escolar que pode ser ofertado "em instituições de ensino superior, públicas ou privadas, com variados graus de abrangência ou especialização, aberta a candidatos que tenham concluído o ensino médio ou equivalente e sido aprovados em

\footnotetext{
${ }^{3}$ Este estudo é resultado das discussões e reflexões da Disciplina Tópicos Especiais em Políticas da Educação Superior e recorte da dissertação de mestrado desenvolvida no Programa de Pós-graduação em Educação da Universidade Federal do Amapá - PPGED/UNIFAP.
} 
processo seletivo" (CAVALCANTE, 2000, p. 15). Portanto, pode ser oferecida por categorias conforme sua organização acadêmica como faculdades, centros universitários, institutos federais e universidades.

Constitucionalmente (art. 207) a universidade é considerada instituição social irradiadora de conhecimentos e práticas, dotada de autonomia didático-científica, administrativa e de gestão financeira e patrimonial, e com obediência ao princípio da indissociabilidade entre ensino, pesquisa e extensão (BRASIL, 1988).

Em relação ao processo histórico, de acordo com Bianchetti e Sguissardi (2017) o modelo de universidade foi instituído posteriormente no mundo ocidental judaico-cristão. Antes, o ensino superior existia em escolas isoladas com oferta de cursos somente para fins utilitaristas e para a garantia de dogmas, dentre outras funções.

Cabe frisar que as universidades passaram por transições de propósitos, dentre eles: para preservar uma velha fé ou granjear adeptos para uma nova fé, para adestrar trabalhadores, para aprimorar o padrão de profissões, para ampliar as fronteiras do conhecimento e mesmo educar os sujeitos (BIANCHETTI; SGUISSARDI, 2017).

Na história brasileira, não foi diferente. Segundo Viola (2013) a universidade surgiu extemporaneamente no país, somente em meados do século $\mathrm{XX}$, pois antes, no início do século XIX, só existiam cursos isolados de ensino superior nas áreas do Direito, da Medicina, e das Engenharias, para atender aos interesses da família real portuguesa e da aristocracia lusitana em território colonial.

[...] é com a chegada da Corte Portuguesa, em 1808, que se inicia a história da educação superior no Brasil. Uma história caracterizada pela tutela e pelo pragmatismo utilitarista dos cursos superiores que foram sendo criados. O primeiro objetivo era atender às necessidades da Corte e lançar as bases para a elevação da qualificação de quadros para determinadas áreas que poderiam auxiliar a retirar o "Reino Unido a Portugal e Algarves" da subalterna condição de dependência de instituições europeias para formar suas elites. (BIANCHETTI; SGUISSARDI, 2017, p. 33-34).

O que se verifica, é que até o final do Império, se consolidou um modelo de faculdades isoladas, na qual os cursos superiores se restringiam apenas a poucos cursos de áreas específicas de conhecimento, vivendo-se do ponto de vista econômico, político, cultural e econômico sob as amarras coloniais, verificando assim laços de extrema dependência e servindo somente aos propósitos de grupos elitizados.

Com a proclamação da República e a Reforma Benjamim Constant (1890) deu-se início às primeiras faculdades particulares, tais como a de Direito da Bahia e Rio do Janeiro e de 
Medicina, de Porto Alegre, além da Escola Politécnica, em São Paulo, e criação de algumas faculdades e institutos científicos (BIANCHETTI; SGUISSARDI, 2017).

Para Cavalcante (2000) ocorreram inúmeras tentativas para implantação do modelo de universidade no Brasil por meio de lutas de vários segmentos, a começar pelos jesuítas, que apesar de tentarem implantar instituições nos moldes universitários, não obtiveram o reconhecimento do Estado.

O que se examina é que apesar de tentativas de criação do modelo de universidade no Brasil, é somente na transição da primeira para a segunda década do século XX que surgem as "universidades efêmeras" livres (privadas) em Manaus (1909), São Paulo (1911), e, em Curitiba (1912). Muitos autores consideram que as primeiras universidades criadas de fato e de direito, por força de decreto do governo federal foram as Universidades do Rio de Janeiro, em 1920 - Reforma Carlos Maximiliano que o governo foi autorizado a reunir três faculdades existentes no Rio de Janeiro numa "universidade" pelo Decreto no 14.343 -; Universidade de São Paulo, criada na década de 1940; e Universidade de Brasília, no início da década de 1960 (VIOLA, 2013; BIANCHETTI; SGUISSARDI, 2017).

Assim, constata-se que desde a chegada da família Real (1808) até a Proclamação da República (1889) foram criadas apenas 14 Escolas ou Faculdades Isoladas; de 1890 a 1930, 02 universidades e 86 Escolas ou Faculdades Isoladas, ou seja, em todo esse percurso histórico, houve um atraso significativo em termos de educação e políticas públicas para educação superior no Brasil. O que se pode aferir é que essas instituições serviram para fortalecer a ideologia dominante, sendo usada como tutela do Estado para exercer seu controle, sendo acessível a uma pequena parcela da sociedade (BIANCHETTI e SGUISSARDI, 2017). Ademais, cabe frisar que

[...] evidentemente nesses apontamentos de aspectos do histórico da universidade no Brasil, o paroxismo, em termos de controle/regulação, será conhecido no período da ditadura, como continuamente de algumas políticas anteriores, que interferiram em uma timidamente proclamada autonomia universitária, mas nunca experimentada na sua radicalidade. Paralelamente, é nesse período de exceção que qualquer voz que se opusesse ao status quo ditatorial foi calada - dentro e fora da universidade - e a implementação de uma política de controle completo foi imposta à universidade, em cujo contexto também passaram a vicejar as iniciativas em termos de privatização - de várias colorações - da educação superior, com estagnação ou refluxo das tímidas iniciativas voltadas à educação pública, gratuita, laica e universal. (BIANCHETTI; SGUISSARDI, 2017, p. 41-42). 
Deste modo, apesar da universidade estar presente desde o século XIX no Brasil, e ter como ênfase sua autonomia, essa de fato, espelha uma política para poucos. Na Constituição Federal de 1988, o art. 207, estabelece essa autonomia didático-científica, administrativa e de gestão financeira e patrimonial. Todavia, três décadas depois, o cenário aponta para uma autonomia universitária cada vez mais restritiva, com interesses crescentes no processo de privatização/mercantilização da educação superior, cuja tendência pode ser a perda das conquistas já normatizadas e a retomada/ampliação da negação ao direito a educação.

\section{O Direito à educação como um direito humano fundamental}

Antes de adentrar no mérito da educação enquanto direito fundamental, faz-se necessário tecer algumas concepções teóricas do que consiste o chamado "direitos humanos", vez que, segundo Dornelles (2013, p. 9), também são conhecidos por outros nomes como direitos do homem, direitos naturais, direitos fundamentais, valores superiores, dentre outros, a depender da teoria e/ou ponto de vista adotado. Trata-se de um tema que tem recebido uma série de significados e interpretações, dos mais diferentes possíveis.

A esse respeito, Bobbio (2004, p. 15-16) comunga do mesmo entendimento, declarando ainda que a expressão "direito do homem” é muito vaga, admitindo-se inúmeras percepções, dentre elas que "são coisas desejáveis, isto é, fins que merecem ser perseguidos, e de que, apesar de sua desejabilidade, não foram ainda todos eles (por toda parte e em igual medida) reconhecidos", ou sendo "aqueles cujo reconhecimento é condição necessária para o aperfeiçoamento da pessoa humana, ou para o desenvolvimento da civilização".

Nesse sentido, Zenaide (2001, p. 42-44) apresenta compreensões dos direitos humanos sob vários enfoques. São eles:

Dimensão Ético-Filosófica - Direitos Humanos como um modo de pensar, sentir, refletir, explicar, agir consigo com outros e com a realidade social, com base em princípios ético-jurídicos dos Direitos Humanos.

$[\ldots]$

Dimensão Econômica e Social - Direitos Humanos como condições materiais e sociais iguais para toda a coletividade;

$[\ldots]$

Dimensão Jurídico-Política - Direitos Humanos como institucionalização do limite de direitos e deveres frente ao individuo, à sociedade e ao Estado, através de mecanismos jurídicos (normas, tratados, declarações, convenções, pactos e leis) e político-institucionais.

$[\ldots]$ 
Dimensão Histórico-Política - Direitos Humanos como espaços, processos e práticas históricas de construção de cidadania democrática, através de ações, lutas e movimentos sociais de atores sociais e institucionais.

$[\ldots]$

Dimensão Educativo-Social - Direitos Humanos como saberes e práticas potencializadores de processos históricos de construção da individualidade, da subjetividade, da cidadania individual e coletiva. (ZENAIDE, 2001, p. 42-45).

No que tange a perspectiva da educação enquanto direito humano, conforme mencionado anteriormente e seguindo diversas diretrizes internacionais, a Constituição Federal de 1988 assegurou em seu artigo $6^{\circ}$ a educação como um direito fundamental, vindo em seu art. 205 declarar como "um direito de todos e dever do Estado e da família" (BRASIL, 1988).

Considerando as perspectivas dos direitos humanos apresentadas por Bobbio (2004) e Zenaide (2010) parece clara a possibilidade de declarar o direito à educação como um direito humano. Constitui-se como algo desejável e merece ser perseguido por ser transformador da condição humana. Permite refletir, pensar, criticar, construir e reconstruir tanto individual quanto coletivamente a sociedade, potencializando o exercício da cidadania.

No âmbito da divisão em gerações/dimensões dos Direitos Humanos, o direito a educação é considerado um direito humano de segunda dimensão, ou seja, são os chamados direitos sociais, onde se espera uma atuação vigorosamente ativa do Estado na entrega de uma prestação efetiva (RAMOS, 2016).

Em relação a conquista do direito à educação, verifica-se que apesar dos diversos dispositivos jurídico-normativos e políticas públicas voltadas para assegurar tal direito, a oportunidade de acesso não alcança a todos - inefetividade dos direitos humanos - e, para aqueles que adentram os espaços escolares as dificuldades para permanência são muitas. No âmbito da educação superior vê-se que o problema é majorado pela desigualdade de condições econômicas e sociais e pela fragilidade de políticas voltadas para assistência e apoio a esses estudantes (CANDAU, 2012; MACIEL; LIMA; GIMENEZ, 2016).

De acordo com as concepções de Candau (2012) e Zenaide (2001) vivemos em uma sociedade que recebeu como herança do período colonial grandes marcas de desigualdades, exclusões e preconceitos, e por vezes, esses direitos consagrados no ordenamento jurídico são violados e até desconhecidos da maioria. Isto é, apesar de muito se falar em direitos humanos, e por conseguinte de um de seus corolários, o direito a educação, a sua inobservância está distante de garantir o êxito de tal preceito constitucional. 
No que diz respeito à educação, segundo Schilling (2008, p. 273) a primeira constatação que todos(as) devem fazer é que o direito à educação consiste em um direito humano. Logo, fundamental para a realização de outra série de direitos, pois na sua concepção a educação enquanto direito fundamental vai muito além da escola ou do conteúdo curricular, mas deve ser compreendida como um projeto de vida, como instrumento para a busca e conquista dos demais direitos humanos de qualquer pessoa.

No dizer de Candau et al (2013, p. 36) trabalhar os direitos humanos "pressupõe uma formação que vai além da sensibilização e da informação. Exige o desenvolvimento de processos formativos que permitam mudanças de mentalidades, valores, comportamentos e atitudes dos diferentes sujeitos que deles participam”. Nessa perspectiva, cabe frisar que a Declaração Universal dos Direitos Humanos, em seu art. 26 ainda prevê que a educação deverá ser

[...] orientada no sentido do pleno desenvolvimento da personalidade humana e do fortalecimento do respeito pelos direitos humanos e pelas liberdades fundamentais. A instrução promoverá a compreensão, a tolerância e a amizade entre todas as nações e grupos raciais ou religiosos, e coadjuvará as atividades das Nações Unidas em prol da manutenção da paz. (ONU, 1948).

Dessas concepções, pode-se extrair inúmeras interpretações, dentre elas a de que uma das tarefas centrais da educação é trabalhar a ideia de igualdade, não no sentido formal, mas considerando todos os aspectos relativos as diferenças, sabendo que em qualquer sociedade há diversidade de raça, cor, sexo, ideologia, religião, cultura, etc., que devem ser respeitadas e valorizadas para que haja uma convivência harmoniosa, com o intuito maior de superar qualquer tipo de ciclo vicioso de discriminação.

A propósito, Bobbio (2004, p. 23) já afirmava que “o problema fundamental em relação aos direitos do homem, hoje, não é tanto o de justificá-los, mas o de protegê-los. Trata-se de um problema não filosófico, mas político". Isto é, para o autor não é suficiente que instrumentos legais-normativos apenas declarem os direitos, mas que siga além, criem mecanismos de proteção e de equidade para proteger e garantir quando esses forem ameaçados ou violados. Portanto, não basta afirmar que a educação se constitui como um direito fundamental é preciso criar mecanismos de garantia efetiva.

Diante desse contexto, o que se observa é que é necessário ampliar os debates em torno dos direitos humanos e expandir para o seio da sociedade e nesse passo, Schilling (2008, p. 
274) comunga do mesmo entendimento, considerando que o ato de promover políticas voltadas para a proteção dos direitos humanos deve ser

[...] fundamental para a realização de uma série de outros direitos. É, assim, a partir dessas práticas, que são um direito em si, que conquistamos o exercício da liberdade de expressão, do acesso à informação que possibilite o usufruto dos direitos civis e políticos, dos direitos sociais e econômicos. (SCHILLING, 2008, p. 274).

Assim, na visão da autora, acredita-se que a partir da conquista de um direito, e nesse caso destaca-se a educação, é possível conquistar muitos outros, dentre eles os civis, políticos, culturais, sociais, de modo a garantir muito mais que ensino, mas a formação de sujeitos críticos e capazes de exercer a cidadania.

Para tanto é válido lembrar que, entendido o direito a educação como direito humano fundamental, um direito social constitucionalmente protegido, estão garantidos também o da igualdade de condições para o acesso e o da gratuidade. Trata-se então de compreender a educação como direito e não um favor (DUARTE, 2007), e por isso sua oferta deve ser com a qualidade para qual ela se destina: formar cidadãos livres e com igualdade de oportunidades e condições de acesso e permanência, em todos os níveis.

Acredita-se assim que, admitida a educação como um direito humano fundamental, as prerrogativas dela decorrentes são protegidas acima de qualquer concepção política que possa desconfigurá-la. Isso que dizer que garantidos estão todos os direitos que se ramificam a partir do direito fundamental a educação, como o da gratuidade, do acesso, da permanência, da qualidade. Trata-se de um direito inaliável, irrenunciável, imprescritível e que obrigatoriamente se efetiva mediante uma prestação programada e ativa do Estado.

\section{Direito à educação superior: um direito de todos?}

De acordo com Silveira (2001, p. 115) "fomos construídos como uma sociedade excludente", pois embora estudos apontem que se vivencia a quarta ou quinta fase/geração/dimensão de direitos, a sua negação parece ser a tônica, pois "apesar de todos esses blocos de direitos circularem em nossa sociedade, e terem avançado no plano da formalização normativa, na prática, possuem uma abrangência limitante. Assim, não basta a existência dos direitos no plano formal, é necessária consciência política para que sua efetivação ocorra, bem como mecanismos de garantia efetivos para que venham a ser respeitados. 
Candau (2012) admite que somos conscientes de que o atual contexto marca uma globalização excludente, com políticas neoliberais, que só estão reforçando fenômenos socioculturais de intolerância e negação do outro, que assume diferentes formas e manifestações e, portanto, articular os direitos humanos constitui-se como uma questão a ser enfrentada.

Lima Júnior (2001, p. 150) menciona que a "constituição de 1988, criada para marcar a mudança de rumo do país no sentido democrático, consagrou o princípio da prevalência dos direitos humanos e da dignidade humana". A partir de então, o Brasil passa a ratificar diversos tratados internacionais de proteção da pessoa humana, dentre eles, importantes documentos que garantem o respeito a diversidade cultural e a implementação de uma educação em/para os direitos humanos.

Mas, ainda que diante desse conjunto de leis, regulamentos, tratados que cercam a sociedade, e em especial a brasileira, que marcam com a promulgação da Constituição Federal o Estado Democrático de Direito, dispondo de um conjunto de normas sobre os direitos humanos, constata-se que o problema que temos diante de nós é buscar qual é o modo mais seguro para garanti-los, para impedir que, apesar das solenes declarações, eles sejam continuamente violados (BOBBIO, 2004).

A esse propósito, trazendo para a discussão o atual cenário da educação superior brasileira, Silva Júnior (2008) alerta que estudos vêm apontando para um modelo de ensino voltado para os interesses do mercado, com muitos questionamentos que envolvem garantias constitucionais relativas ao direito a educação, e nesse processo

[...] a universidade, outrora organizada como uma instituição que, além da formação de profissionais, se ocupava da produção do conhecimento, da extensão e prestação de serviços, transforma-se celeremente em organização que, nas últimas décadas, passa a oferecer produtos educacionais em resposta às demandas que lhe são postas, acentuadamente de fora do Brasil. Ao mesmo tempo em que a mundialização aponta, entre outros, para programas de empreendedorismo e inovação, seus processos econômicos tendem a desestabilizar a já bastante precária autonomia acadêmica e institucional. Este processo também pode ser observado no Brasil, onde a economia dos anos recentes e em curso está mudando de forma estrutural a educação superior em geral no país, com ênfase no setor público federal. (SILVA JÚNIOR, 2017, p. 223).

Isto é, para o autor, a universidade caminha para uma provável ausência/negação desses direitos. A corroborar com esse entendimento, Minto (2006) assevera que com a perda desse espaço histórico para as políticas públicas sociais, gestamos um novo tipo de política de 
caráter assistencialista, na qual o Estado se torna apenas gestor dos serviços, delegando ao setor privado ou a sociedade civil, em consonância com os interesses dominantes, o que seria seu papel.

Bianchetti e Sguissardi (2017, p. 87) reforçam o processo de recuo do Estado frente à efetividade do direito a educação - com alcance para o eixo da educação superior - e nos lembram que há uma "gradativa desresponsabilização estatal" quando se transforma de Estado Educador para Estado controlador, de forma a descumprir princípios básicos deste direito fundamental.

Assim, a partir desse cenário, observa-se que o poder público vai alterando o dever de atuar diretamente na promoção/oferta da educação superior gratuita e universal para desenvolver formas regulatórias que acabam por transferir a oferta da educação em grande escala à iniciativa privada.

Silva Junior (2017, p. 227) corrobora esta afirmação dizendo que em "2010, dos cerca de 5,5\% milhões de alunos matriculados no ensino superior, $11 \%$ estudavam em IES privadas (sem fins lucrativos) e 62\% em IES particulares (com fins lucrativos); apenas 27\% estudavam em IES públicas federais, estaduais ou municipais".

Foi nesse contexto que a educação superior se tornou um setor cada vez mais orientado ao mercado com o objetivo de atender às crescentes exigências de valorização do capital financeiro. A mercantilização institucional realizada neste processo induz as políticas para este nível educacional no setor público a participar na arena competitiva global da ciência produtora de conhecimento matéria-prima, bem como exige a mobilidade acadêmica de estudantes e professores, caracterizando, desta forma, o processo de internacionalização da educação superior. [...], uma vez que a educação superior passou a ser considerada uma mercadoria a ser comercializada livremente. (SILVA JÚNIOR, 2017, p. 231).

Logo, na visão do autor, a educação superior vem cedendo às exigências do capital, passando o ensino a ser considerado como mais um produto no mercado, ou como afirmam Bianchetti e Sguissardi (2017, p. 14-15) "transformado em mercadoria/commodity ${ }^{4}$ submetida ao crivo do mercado, em que a Bolsa de Valores constitui-se no "altar" onde essa metamorfose chega ao paroxismo", além de estar ocorrendo um crescimento impactante nas matrículas em IES privadas em comparação às matrículas nas IES públicas. As consequências no cenário educacional são muitas, sendo uma delas a de que

\footnotetext{
4 Os autores criaram essa expressão (neologismo) para explicar sobre a escala privatizante na educação superior/universidade, na qual se utilizam do termo commodity, que significa mercadoria em estado bruto ou produto primário, de origem agropecuária, vegetal ou mineral, produzido em larga escala, cujos preços submetem-se à oferta e procura para comparar o cenário atual da educação superior.
} 
[...] os estudantes brasileiros e os professores tendem a ver na educação superior um meio para um fim pragmático profissional num contexto de vigência de rankings universitários, ensino a distância, pós-graduação flexível e programas de atualização. Esta perspectiva impulsionada pelo mercado desafia a educação superior brasileira. (SILVA JÚNIOR, 2017, p. 235).

Assim, o que se constata é que embora estudos apontem para a expansão da educação superior no Brasil, com ampliação de matrículas e com uma aparente educação acessível à todos, o que se percebe é o destaque para o crescimento das IES privadas, cujo aporte financeiro público encarrega-se da margem de lucro positiva - em contrapartida ao endividamento das famílias e população jovem; a crescente precarização das IES públicas; ou a simples oportunidade de acesso sem dar garantias para a permanência e sucesso na conclusão do curso superior.

Outra questão que chama atenção é a velocidade de políticas e Instituições voltadas apenas para o propósito de "diplomar". O direito humano fundamental de ampliar o número de pessoas com formação superior para pleno desenvolvimento humano, capaz de tornar-se sujeito que pode reconstruir relações sociais, perde-se para o que Bianchetti e Sguissardi (2017) chamam de ampliação numérica de alunos-cliente, transformando a educação superior num modelo que era exclusivo de empresas mercantis. Tem-se uma expansão da educação superior que transformou pessoas sem diplomas em invisíveis diplomados.

Portanto, o cenário das educação superior é menos de cumprir sua função social e mais de oferecer produtos como respostas ao que o mercado exige (conhecimento matéria-prima), se curvando para o capital e não mais produzindo conhecimento para uma formação humanística, que se preocupa com o conhecimento revertido em práticas sociais e institucionais que promovam a emancipação dos sujeitos.

Temos, portanto, uma educação superior negada, pois o verdadeiro direito humano fundamental à educação superior não se efetiva como entrega de um produto; não significa diplomar; não se perfaz em instituição precarizada; não se encerra com o simples ingresso.

O direito a educação superior a todos e todas engloba uma posição ativa do Estado, própria das exigências destinadas aos direitos sociais. Seu papel é de oferecer o suporte necessário para a real tarefa da educação superior: a oferta da formação humana integral e sua ampliação por meio de uma política de expansão mais gratuita e universal e menos onerosa e limitante. 


\section{Considerações finais}

A história da educação superior, em especial das universidades públicas tem revelado uma educação tardia na sociedade brasileira, e, embora constitucionalmente a educação seja reconhecida como um direito humano fundamental, e a oferta gratuita ainda seja uma garantia no país, o investimento crescente destinado às IES particulares neutraliza uma verdadeira política pública de acesso, gerando uma multidão de invisíveis diplomados e endividados.

Quando o setor educacional é orientado pelo mercado e o conhecimento transforma-se em matéria-prima não podemos garantir um direito a educação superior para todos e todas, pois a formação superior está destituída do seu caráter original. O direito, portanto, é negado.

Essa configuração da educação superior acentua o círculo vicioso da desigualdade e retira do espaço próprio da produção do conhecimento e do pleno desenvolvimento humano a problematização dos processos de exclusão e negação aos direitos.

Observa-se, portanto, uma educação superior cuja expansão mascara sua finalidade maior, que é o acesso e conclusão qualitativo, não somente quantitativo. É do direito humano a uma educação de qualidade que a Constituição Federal estabelece e determina que seja cumprido pelo Estado. As garantias de formação integral, de acesso e permanência, de gratuidade é que ensejam o verdadeiro direito a educação superior extensivo a todos e todas.

\section{REFERÊNCIAS}

BOBBIO, Noberto. A era dos direitos. (Tradução de Carlos Nelson Coutinho). Nova ed. Rio de Janeiro: Elsevier, 2004.

BIDERMAN, Maria Tereza Camargo. Dicionário didático de Português. $2^{\mathrm{a}}$ ed. - São Paulo: Ática, 1998.

BRASIL. Constituição (1988). Constituição da República Federativa do Brasil, de 05 de outubro de 1988. Disponível em:<http://www.planalto.gov.br/ccivil_03/constituicao/constitui \%C3 \%A7a o.htm>. Acesso em: 01 jan. 2017.

BRASIL. Senado Federal. Lei no 9.394/1996. Estabelece as diretrizes e bases da educação nacional. de 20 de dezembro de 1996. Disponível em: <http://www.planalto.gov.br/ccivil_ 03/leis/L9394.htm>. Acesso em: 18 jan. 2017.

CANDAU, Vera Maria. Didática crítica intercultural: aproximações. Petrópolis, RJ: Vozes, 2012. 
CANDAU, Vera Maria. Diferenças culturais, interculturalidade e educação em direitos humanos. Educ. Soc., Campinas, v. 33, n. 118, p. 235-250, jan./mar. 2012. Disponível em http://www.cedes.unicamp.br Acesso em: 12/01/2018.

CANDAU, Vera Maria; et al. Educação em Direitos Humanos e formação de professores(as). 1 ed. São Paulo: Cortez, 2013.

CAVALCANTE, Joseneide Franklin. Educação superior: conceitos, definiçõos e classificações. - Brasília: Instituto Nacional de Estudos e Pesquisas Educacionais, 2000.

DORNELLES, João Ricardo W. O que são direitos humanos. São Paulo: Brasiliense, 2013 (Coleção primeiros passos).

DUARTE, Clarice Seixas. A educação como um direito fundamental de natureza social. Educ. Soc., Campinas, vol. 28, n. 100 - Especial, p. 691-713, out. 2007. Disponível em http://www.cedes.unicamp.br Acesso em: 15/01/2018.

LIMA JÚNIOR, Jayme Benvenuto. O sistema global de proteção dos direitos humanos. In: ZENAIDE; Maria de Nazaré Tavares e DIAS, Lúcia Lemos. (Orgs.). Formação em direitos humanos na universidade. João Pessoa: Editora Universitária, UFPB, 2001.

MACIEL, Carina Elisabeth; LIMA, Elizeth Gonzaga dos Santos; GIMENEZ, Felipe Vieira. Políticas e permanência para estudantes na educação superior. RBPAE - v. 32, n. 3, p. 759 - 781 set./dez. 2016.

ONU. Declaração Universal dos Direitos Humanos, 1948.

RAMOS, André de Carvalho. Teoria geral dos direitos humanos na ordem internacional. 6. ed. São Paulo: Saraiva, 2016.

SILVA JÚNIOR, João dos Reis. The new Brazilian university: a busca por resultados comercializáveis: para quem?. 1. Ed. - Bauru: Canal 6, 2017.

SILVA, Aida Maria Monteiro. Educar em direitos humanos no brasil: o processo de implantação de políticas públicas, 2013. Disponível em: <<

http://www.anpae.org.br/IBERO_AMERICANO_IV/GT3/GT3_Coimunicacao/AidaMariaMo nteiroSilva_GT3_integral.pdf $\gg$. Acesso em: 18/12/2017.

SILVEIRA, Rosa Maria Godoy. 500 anos de uma cidadania excludente. In: ZENAIDE; Maria de Nazaré Tavares e DIAS, Lúcia Lemos. (Orgs.). Formação em direitos humanos na universidade. João Pessoa: Editora Universitária, UFPB, 2001.

SCHILLING, Fávia. O Direito à Educação: um longo caminho. In: BITTAR, Eduardo C. B. (Coord.). Educação e metodologia para os direitos humanos. São Paulo: Quartier Latin, 2008. p. 273-284.

VIOLA, Solon Eduardo Annes. A educação superior: compromisso com os direitos humanos. In: SILVA, Ainda Maria Monteiro. (org.). Educação superior: espaço de formação em direitos humanos. São Paulo: Cortez, (coleção em direitos humanos), 2013. 
ZENAIDE, Maria de Nazaré Tavares. Os desafios da educação em direitos humanos no ensino superior. In: SILVA, Ainda Maria Monteiro; TAVARES, Celma (org.). Políticas e fundamentos da educação em direitos humanos. São Paulo: Cortez, 2010.

ZENAIDE, Maria de Nazaré Tavares. Construção conceitual dos Direitos Humanos. In: ZENAIDE; Maria de Nazaré Tavares e DIAS, Lúcia Lemos. (Orgs.). Formação em direitos humanos na universidade. João Pessoa: Editora Universitária, UFPB, 2001.

\section{SOBRE AS AUTORAS:}

\section{Jemina de Araújo Moraes Andrade}

Mestra em Educação pela Universidade Federal do Amapá (UNIFAP); professora efetiva EBTT do Instituto Federal do Amapá (IFAP), Macapá, Amapá, Brasil; Doutoranda do Programa de Pós-Graduação em Educação na Amazônia - EDUCANORTE (Doutorado em Associação); membro do Grupo de Pesquisa "Estudos em Direitos Humanos, Educação e Sociedade”. E-mail: jemina.andrade@ifap.edu.br

(iD http://orcid.org/0000-0003-0901-6837

\section{Helena Cristina Guimarães Queiroz Simões}

Doutora em Educação pela Universidade Federal de Uberlândia (UFU); Professora da Universidade Federal do Amapá (UNIFAP), Macapá, Amapá, Brasil; Programa de PósGraduação em Educação (Mestrado) da UNIFAP e no Programa de Pós-Graduação em Educação na Amazônia - EDUCANORTE (Doutorado em Associação); Líder do Grupo de Pesquisa "Estudos em Direitos Humanos, Educação e Sociedade". Correio eletrônico: simoeshcg@gmail.com

(iD http://orcid.org/0000-002-2170-5574

Recebido em: 31 de julho de 2018 Aprovado em: 10 de janeiro de 2020 Publicado em: 27 de janeiro de 2020 